\title{
Are Summer Institutes Funded By FHWA And State Departments Of Transportation Effective? Case Studies Of Evaluation And Learning Strategies
}

Chandra Aleong, Delaware State University John Aleong, University of Vermont

\begin{abstract}
For the last three years Delaware State University (DSU) and the University of Vermont (UVM) have implemented a new approach to a summer program or "Institute" that emphasizes evaluation and accountability. Beginning in 2005, both institutes changed the focus of their programs to fulfill not only the primary objectives of instilling inquiry and project-based learning in the field of transportation but to incorporate rigorous evaluation criteria. If goals are very narrowly defined, that is, counting the number of students entering a career in transportation, then there are limitations. Students in the $9^{\text {th }}$ through $12^{\text {th }}$ grades are still experimenting with different career paths. Summer programs like the Summer Transportation Institute enable students to get to post-secondary education. Evaluation is necessary to ensure that funds are spent effectively but success should be measured on several fronts.
\end{abstract}

Key words: Transportation; evaluation; accountability; case studies.

\section{INTRODUCTION}

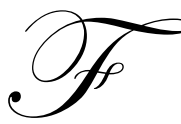

or the last three years Delaware State University (DSU) and the University of Vermont (UVM) have implemented a new approach to a summer program or "Institute" that emphasizes evaluation and accountability. The students in both programs are similar in age group, grade level, and academic standing. Those who attend the DSU Institute are required to have at least a 2.5 GPA while the UVM attendees are participants in a federal program called "Upward Bound". Federal Highway Administration (FHWA) provides most of the funding while the state departments of transportation such as Delaware Department of Transportation (DelDOT) and Vermont Agency of Transportation (VTrans), provide a smaller percentage of funds and are the principal donors of in-kind services. Beginning in 2005, both institutes changed the focus of their programs to fulfill not only the primary objectives of instilling inquiry and project-based learning in the field of transportation but incorporating more rigorous evaluation criteria than had been used in the past. The purpose of this paper is to discuss the performance and evaluation of the programs.

\section{A DESCRIPTION OF THE PROGRAMS AND THE STUDENTS}

The goals and objectives of the Institute are to increase interest in disciplines and careers related to transportation. This is the $12^{\text {th }}$ year for the Institute at Delaware State University and the $3^{\text {rd }}$ year at the University of Vermont. The teachers are university faculty, education majors, and professionals with many years of experience. Classroom activities include lectures, assignments, presentations, and field trips, all related to the field of transportation but with the focal point of consulting on a major project. The intent is to build knowledge and skills in specific content areas such as civil engineering, environmental sciences, transportation planning and finance, and GIS (Geographic Information Systems). 
The funding agencies give a lot of leeway to grant participants, usually university faculty, to try new techniques. This results in great diversity and creativity in the approaches to training. It is different from preparing to teach a typical undergraduate level course because the scope is broad, the approaches are varied and the student population is unique. Active participation from faculty and staff and interaction of students with professionals in the field are key elements. Workshops, activities, and field trips are an integral part of the planning and delivery and are as important as the academic content. The backdrop to this is the fact that the students range in age from eleven to fifteen and come into the program not knowing very much about the area of transportation and might not have ever thought about a career in transportation.

The students are at an age when young people are beginning to think about careers and academic paths to pursue in college. The expectation is that the exposure to non-traditional subjects like transportation in a non-school environment would pique their interest and enthusiasm. The more immediate expectation is for students to complete advanced science, mathematics, and management courses in high school that would prepare them for post-secondary education and, ultimately, to select a major that is transportation-related.

Students come from the surrounding area high schools and are screened based on GPA and letters of recommendation from teachers and counselors. The program at Delaware State University has been in effect for ten years and the summer of 2006 was the $10^{\text {th }}$ anniversary for the Institute. In years prior to the 2005 summer program, the program was residential and followed a set format of guest speakers, field trips, and classroom lectures in English Grammar, Science, and Computer Skills. There was no unifying project and the only rubric for accountability purposes was an essay that was judged by an off campus board member. The major motivator was an out of town weekend field trip from Dover, Delaware to Boston, Ottawa, New York or some other city.

\section{Objectives And Scope Of Evaluation}

There was need for intervention and evaluation based on feedback from the granting agency. The first major change was the adoption of the project-oriented approach and more rigorous evaluation related to testing the effectiveness of the Institute. Tests were designed to determine the effectiveness of all aspects of the program; academic content; field trips; workshops; presentations; and the overall interest of the participants in fulfilling the goals of the Institute.

One of the main purposes of evaluation is to enable the designers of innovative programs to learn and make assessments about (a) the initial assumptions of the goals of training; (b) the implementation techniques; and (c) the outcomes of the training. The three-tiered process of setting goals, implementing them, and finally measuring outcomes is an iterative as well a dynamic process. Goals must be compared with outcomes at every stage to measure success of each activity, field trip, and learning experience as well as the overall program. Evaluation measures are designed to match the goals of the granting agencies as well as those of the administering institution. Since each institution has the leverage to develop its own program there is great diversity in the way federal programs like the Summer Transportation Institute are planned and administered. The common objective, however, is to raise awareness of the transportation industry and to encourage students to pursue careers in the field of transportation.

\section{What is "Performance"?}

The task of judging "performance" is very broad and varied. For example, a long-term performance measure could be the creation of interest generated by the Institutes such that graduates of the program decide to change majors to engineering or a specific transportation-related area, whereas previously, they were thinking of pursuing other career goals. This was the case with two students who graduated from the DSU program in the last four years.

A more realistic goal, however, might be to improve the students' knowledge of college preparation subjects by teaching academic content areas such as math, science, English, and communications skills in a less stressful environment outside the regular classroom setting. Incorporating and integrating transportation issues and 
problems with the academic content have additional value-add in that projects and assignments demand critical thinking and application of knowledge to real life problems. Students become involved with professionals in the field looking at ways to solve problems. This approach raises awareness of the transportation industry and might encourage students to pursue careers in the field of transportation. The problem with this approach is that measuring the effectiveness of meeting stated objectives of the grant requires a more robust definition of success.

The placement of these programs at academic institutions indicates that the funding agencies expect a broader definition of education to take place rather than a more professional or job-training approach. Thus providing the students with academic content as well as career-related information fulfills a multiplicity of goals. In the end the students receive activity-packed programs with multiple objectives, implementation systems and outcomes. This paper captures the essence of two individual programs that are representative of the close to fifty Institutes that take place across the country every summer. The cost to the Federal and State governments is close to four million dollars annually and is even higher if the cost of the overhead at the federal and state agencies is included.

\section{Definition Of Outcomes}

The intended outcomes for the transportation and related field trips, workshops, and presentations at Delaware State University and University of Vermont were as follows:

$\begin{array}{ll}\text { - } & \text { Objectives were clear } \\ \text { - } & \text { Related to transportation } \\ \text { - } & \text { Examanized } \\ \text { - } & \text { Audio/Visual Aids } \\ \text { - } & \text { Adequate time for audience participation } \\ & \text { Number of speakers were adequate }\end{array}$

The scale used in the study was a four-point scale from: Strongly Agree; Agree; Disagree; to Strongly Disagree. A forced choice where the option was "neither agree nor disagree" was not available because of the age of the respondents. The project directors felt that the students needed to take the time to think about the events and scale them rather than opting for the easy way out. Also, the responses gave the faculty and staff the input to make changes on a timely basis.

The intended outcomes for the academic part of the program, such as the Science, English/Communications, and Math were very comprehensive and for each area there were more specific objectives. For example in science an example of the pre and post-assessments were as follows:

- Identify and describe the steps of the scientific method

- $\quad$ Write down everything you know about light and its properties

- $\quad$ Write down everything you know about electricity

- $\quad$ Document everything you know about the metric system

- $\quad$ Measure the dimensions of a cube, rectangle etc.

In the DSU program the Science, Math and English components were designed to meet the individual needs of each student. This posed several problems for the instructors since the students in the program ranged from the $9^{\text {th }}$ to the $12^{\text {th }}$ grades and were at varying levels of competence. That meant more individualized attention, assignments, and testing. However, it gave the student teachers and academic aides in the DSU program the opportunity to develop their skills and to practice a teaching methodology called "Differentiated Instruction" which the State of Delaware requires them to utilize in classrooms when they graduate. Individual outcomes for each subject became the basis for making adjustments to the subject matter taught. 
The University of Vermont had a variety of speakers and academic content modules. The main difference was the lack of a unifying project as a vehicle for demonstrating transportation-related material. Instead the presentations, fieldtrips, and workshops as well as the modules in algebra, statistics, geometry and English provided the forum for the learning experience and for evaluating outcomes. Although not blatantly stated, both programs were influenced by theories of learning in the field of Education as will be seen in the review of the some of the authors in the following section.

\section{LITERATURE REVIEW}

Literature on the topic of program evaluation and improving educational performance is broad and varied. This review attempts to highlight several areas of interest, some of which include the underpinnings of educational theory as well as the rationale for using the responsive evaluation techniques.

Authors like Malcom (2006) have stated that, "non-existent or poor early science instruction can affect students' attitudes toward science and their future willingness to take elective courses in science". Introducing students to the science and engineering associated with transportation in an interesting and activity-oriented environment should motivate them to consider this as an option for future employment and take related elective courses. However, training also means paying attention to the teachers. Saphier (2005) is of the opinion that student achievement, interest, and motivation "hinges on improving the teaching expertise of the individual teachers who work with the children". The project director of each Institute spearheads the learning process for the faculty, staff, and guest lecturers. Reinforcing the learning that takes place during the summer, calls for additional experiences during the academic year. This is the role of the project directors, who are generally faculty engaged in teaching, research and service. The Institute is not considered only as a means of compensation for faculty during the summer, but to provide raw material for research and service for tenure and promotion.

Generally the population served by the Summer Transportation Institute consists of students from low socio economic environments. Darling-Hammond (1996) has stated that that "too few of our teachers have enough expertise and our poorest children have the largest share of low-expertise teachers". The Summer Transportation Institute is another forum provided by Delaware State University, a member of the Historically Black Colleges and Universities, and the University of Vermont through the "Upward Bound" program to resolve the problems facing the neediest in society as well their educators. The faculty and staff for the Institutes are members of the Colleges of Education, Engineering, Arts and Sciences, just to name a few, and are aware of the importance of designing their lectures for the multicultural as well as the inclusive classroom. As James Banks (2001), a leading expert in multicultural expert points out, growing ethnic and cultural diversity requires rethinking school curricula.

Recent efforts to improve learning and education as a whole have emphasized experiential learning and action research. John Dewey (1938) described this as "the need for forming a theory of experience in order that education may be intelligently conducted upon the basis of experience". The impetus for change resulted from the urgency to be more experiential. The curriculum for the Institute at DSU had grown stale and was too passive in its approach. The study of transportation was a great channel for testing the theories of Dewey and the progressives who emphasized that schools should teach learners how to solve problems and inquire about their natural and social environments. (Gutek, 1997)

Embedded in the instruction were assessment tasks that can be categorized as responsive evaluation. Stake (1973) felt that responsive evaluation "sacrifices some precision in measurement, hopefully to increase the usefulness of the findings to persons in and around the program". Shavelson (1992) felt that observation during instruction as well as collecting some of the artifacts of instruction meant that assessment flowed directly from the instruction. While reliability and validity are critical to methodological rigor, they require the evaluator to be objective and neutral. The nature of the programs and students did not lend themselves to such rigor. 


\section{Integration Of STI Program Design With Learning Theories}

The instructional programs used for the Institutes were strongly influenced by research related to the theory of constructivism as well as by John Dewey's experiential-based learning ideals. Both these influences have a common principle that individuals cannot simply be given knowledge, but must create knowledge based on prior knowledge (Armstrong et al, 2005). The relevance here is that conditions for learning must be learner-centered and problem-centered.

The challenges for both Institutes were to pose complex, complete, and "authentic" problems related to transportation to the students and then provide guidance to help them gain the knowledge needed to solve them. In 2006 the students at DSU had to determine the optimum places to locate ramps on Interstate 95 for commuters to access the "Riverfront", a major development project in the State of Delaware. By embedding the problem or project in the larger context of land, air, and sea transportation, the learning philosophy was to utilize a single, integrated process. Students had a real need to know the engineering, math, science and community-related issues to develop responses to questions posed, and to determine alternatives for the placement of roads and bridges. The onus was on them to do research, ask questions, and seek out answers from the faculty, staff, and visiting professionals from the transportation agencies. This meant that they were actively engaged in the learning process. In 2007, the Dover Signalization Project enabled the students the opportunity to research traffic signals, fiber optics, and the requirements of the American Disabilities Act in the design of sidewalks and traffic signals.

At UVM the students were involved in hands-on archaeological digs, scavenger hunts, bicycle rides, and several field trips related to the flora and fauna affected by bridge and road development. This led to several heated discussion about the rationale for delaying a major road or bridge project because of the spawning of a particular species of turtle or bird. They also were exposed to presenters from the National Security Agency and the Army who gave them a real-life lesson on logistics as it pertained to the war in Iraq.

In addition, the social network generated from the team structure, and the competitive nature of the assignments, meant that they had to collaborate to win the support of the judges at the final presentation. The projects were deliberately challenging making it unlikely for any one individual to find the solution working alone. Overall, the assignments were designed around constructivism principles, which meant having a learning environment filled with content knowledge, discussions, lab activities, and field trips. In the UVM program the students competed in a very competitive bridge development assignment with other summer camp students.

The programs were only different in one respect. The DSU program hooked everything to one major project. The UVM Institute was not unifying in theme but covered the same breadth of topics in separate components. The unifying subject was the multifarious and indispensable importance of transportation in everyday activities and the role that the students could play in being involved in this area as a career opportunity.

\section{Assessment And Accountability}

One of the most important changes in the program was the incorporation of assessment and accountability measures. The bases for evaluation were primarily contextual, such as presentations, quizzes, and team interactive projects. Traditional evaluation techniques emphasizing scientific methods and quantitative measurement did not lend themselves either to the nature of the Institute or the students.

While there were always measures to assess the Summer Transportation Institutes, the two program directors at DSU and UVM wanted to implement more relevant evaluation techniques. Cunningham (1997) has stated that the process of ascertaining what students learn is a continuous and on going process. The directors felt that to instill a culture of discovery and learning, the faculty and staff must emphasize how well the students were able to solve problems instead of traditional testing techniques which measure what they had been told.

Another measure of learning was to ensure that each student made progress. Taking into account differences in prior knowledge is a key component of constructivism. The faculty and staff differentiated tasks and 
instruction. For example, knowledge of Power Point, ability to read maps, and knowledge of mathematics were just some of the areas that differed among the students. The challenge was to ensure that each individual in this mixed group of $9^{\text {th }}$ to $12^{\text {th }}$ graders was able to engage with other team members, participate actively, increase learning, and be an integral part of the success of the group. In addition, the pre and post-tests in the academic content areas ensured that there were incremental changes in learning based on tests, assignments, and class presentations.

\section{METHOD, PARTICIPANTS, DATA SOURCES}

Throughout 2004, 2005, 2006, and 2007 DSU and UVM continued to collect and refine data on the level of knowledge of the students, both prior to and on completion of the Institute. The data used to inform the DSU part of the study came from 65 students, 18 the first year, 15 the second year, 17 the third year and 15 the fourth year. Data sources included students' preparation documents, observations of in-class presentations, written reflections, final reports, videotapes and one on one interviews. We used standard qualitative data analysis techniques through coding to examine the data sources to understand how much the students had improved. Faculty and staff notes, in-class presentations, interviews and videotapes as well as reflective journals were the primary data sources for qualitative data. Throughout the analysis of data, we asked, did they understand the assignment? Did they do adequate research? Did their presentation adequately represent what they had learnt? The main criteria used for assessment and analysis, were technical competencies, communications skills, teamwork, and leadership.

The data was coded using narrative and epiphanic analysis (Denzin, 1989) to identify significant changes in knowledge and expertise. We looked for broad categories and recurrent themes and also, identified aspects relevant to the approaches used to promote learning such as constructivism or the Dewey-inspired learning methods.

\section{DATA ANALYSIS}

The performance criteria for the students were quantitative and qualitative. They measured the difference between what they knew about these topics both when they entered and when they exited the program. Measurements were based on specific knowledge both from interrogation after the lectures, presentations, and comprehensive reports given by the students. An analysis of the ratings of each speaker, as well as reflections by the students on the overall program enabled us to triangulate the findings.

The subject areas examined for improvements in performance are listed below.

\section{Subject Areas}

Materials Sciences (MS)

Transportation Law (TI)

History of U.S. Highway System (HHS)

Transportation Finance (TF)

Engineering Math (EM)

Environmental Issues (EI)

Archaeological Issues (AI)

Real Estate Issues (RE)

Contract Administration Issues (CAI)

Public Relations Issues (PR)

Geographic Information Systems (GIS)

\section{Qualitative Review}

\section{The Students}

Most of the students were unclear about the careers they were planning to pursue when they left high school but their reflection statements at the end of the program indicated a deep interest in areas of science and management related to transportation, something that was not the case when they began. It will take a few years to 
follow this cohort to ascertain whether the career interests are as passionate as when they left the program but the intervention of the educational approach at DSU definitely had an impact in their thought process. One very brilliant student who was unclear about the type of career he would pursue said the following, "Before I came to this 2005 Transportation Camp, I was completely unaware of the many career opportunities that exist in the field of transportation" He then went on to name the career opportunities that he had become aware of such as public relations, bridge design and construction, materials research, management, computer science, and traffic control. A testimony to the effectiveness of the interest that was generated was the comment on bridge design, "We all travel on bridges, but if it had not been for the project we did in class with designing and trying to keep the costs down at the same time, I would never have considered the finances of these things".

Another student came in with great expectations, and it was very satisfying to read in her reflection statement that they were fulfilled. She stated the following, "I planned to learn as much as possible about the following areas through this program; Leadership; Management; Group Work; and Transportation. As a participant, I enjoyed the program to the fullest. I had a lot of words of encouragement from faculty member, program directors, and academic aides. I will always recommend people to go to a summer program like this. I really appreciate what the program has done for me. I am glad that at the end of the program I was able to achieve all the goals I had set for myself". Most of the students wanted to return to the Institute the following year but of course new students had to get first preference.

\section{Quantitative Analysis}

At UVM the courses evaluated were Mathematics, Statistics, Science, English, American Sign Language, Spanish, Bridge Design, GIS, GPS, Traffic Analysis and Simulation Model Development. All the field trips organized by the Vermont Department of Transportation and the Vermont Air National Guards were also evaluated. The overall evaluations are shown in Appendix 1 and Appendix 2. Based on the criteria listed above, $80 \%$ of the students in the UVM cohort strongly agreed; that the program was well organized; that they were academically challenged; and that their response to the program was positive. The DSU response was similar with $85 \%$ of the students agreeing to an overall positive experience.

In the more specific areas such as helpfulness of the staff the numbers are $73 \%$ for UVM and $86 \%$ for DSU. This data is useful because of its contextual nature. Some of the students' negative responses to the staff and faculty not giving them opportunities to express their opinions must be interpreted with background information. A few students felt that because they were not in a traditional classroom setting, they should not be told what to do or be given difficult assignments. This negative feedback is useful data and can be interpreted in different ways, such as "Good, we got them to work despite the odds" or "We have to find ways to get everyone to voice their concerns".

Throughout the years as well as at both locations, the responses to the speakers and the field trips were very positive. The speakers from Federal Highway Administration as well as the State Departments of Transportation are primary agents of change in planning and implementing the Summer Transportation Institutes. Whether the topic is materials science, real estate, law, finance, environmental science, GPS, or traffic management, a common response is that the presentations, field trips, and hands-on experimentation are pivotal in making the programs enlightening and successful. The anxiety of the project directors at the start of every year is quickly replaced with relief when the professionals begin interacting with the faculty, staff, and students. The synergy translates into teamwork among all the parties making the program planning and implementation a smooth flow rather a tedious process.

\section{Professionals From The Granting Agency}

Another performance measure was the excitement and interest of all the Delaware and Vermont Departments of Transportation and FHWA professionals who participated. They were very positive about the whole process and the feedback they received from everyone. They felt satisfied that they had made a contribution and are always eager to begin planning the next year's program earlier so they could have even more of an impact. Of course the best measure of effectiveness is the willingness by FHWA and State Departments of Transportation to continue funding the Institute for another year given the scarcity of money for other state and federal projects. 


\section{CONCLUSIONS, LIMITATIONS, AND QUESTIONS TO CONSIDER}

The experiments used for the Summer Transportation Institutes at both universities were resounding successes both from an educational as well as a behavioral perspective. The problems posed were context driven and the methods of teaching were influenced by the current theories and practices in the field of Education. These include discussion to elicit ideas and to reinforce knowledge; solid grounding in the core content knowledge; and enforcing accountability. At the same time, the formation and nurturing of teams throughout the process reinforced exemplary behavior and set the stage for a competitive environment that was positive in encouraging higher level thinking and stronger social ties. In the final analysis, the objective of illustrating general principles about very complicated topics in engineering, law, and economics as they relate to transportation was presented as a puzzle with the intent of encouraging students to bridge the gap from the abstract to the concrete.

The STI project directors introduced structure and accountability to a summer program that was haunted in years prior to 2005 with anecdotes of horrible fights and bad behavior. The index of horror in the DSU's case was which student should be dismissed from the program that day. Beginning with the 2005 program, the topic became the extent of progress each group was making and who was going to win the prize. The competitiveness aspect was encouraged in a positive way by emphasizing content and providing support to enable the learning process. All members of the faculty and staff were involved with the project and integrated their curriculum and assessment efforts to ensure that the final product was one that the professionals of the granting agencies would consider to be worthwhile for continued funding and participation. The interest and involvement of the students were so high that they gave up fun trips in the final week to work on their project. This is something that would never have happened in prior years where the emphasis was on extra-curricular activity.

\section{Future Directions}

Evaluation and accountability measures will continue to be embedded in the culture of the Summer Transportation Institutes at both institutions. It is very clear that the grant will not be renewed unless the goals of the funding agencies are accomplished. That leads to accountability on all fronts since faculty, staff, and students will not get the compensation and experiences that are the rewards from the program.

In 1980, Williams, Aleong, Merrow and Morse designed and implemented a program evaluation methodology for the US Food Stamp Program (USDA) for the states of Vermont and Nevada. Pretest and two post tests were administered. The second post test was administered six months after the first post test. A measure of Learning Effectiveness (LE) which is the relative change in the first post test and pretest scores was calculated. The Retention Effectiveness (RE) which is the relative change in the two post test scores was calculated. New statistical tests were given to evaluate the statistical significance of the LE and RE measures. In the future, Summer Transportation Institutes might need to develop some of the measures to determine whether the programs are having any long term impact.

Summer programs, like the Summer Transportation Institute, enable students to get to post-secondary education. Whether they choose transportation in the first, second, or third phases of their careers would mean following cohorts of students for a very long time. While this is possible it is not feasible. It seems that success should be measured on several fronts. The Federal Highway Administration, the State Departments of Transportation and the universities are making a contribution to the productivity of future workers, as well as adding to the education of the citizenry in general. There is a multiplicity of stakeholders in the process and everyone benefits thanks to funding opportunities like the Summer Transportation Institute.

\section{REFERENCES}

1. $\quad$ Armstrong, D.J., Henson K.T., Savage, T.V. Teaching Today: An Introduction to Education $\left(7^{\text {th }}\right.$ Ed). Pearson Merrill Prentice Hall, 2005.

2. Banks, J. An Introduction to Multicultural Education ( $3^{\text {rd }}$ Ed.). Boston: Allyn \& Bacon, 2001.

3. Cunningham, G. Assessment in the Classroom. Routledge, (UK), 1997. 
4. Darling-Hammond, L. . Equity Issues in Performance-Based Assessment. In M. T. Nettles \& A. L. Nettles (Eds.), Equity and excellence in educational testing and assessment (pp. 89-114). Boston, MA; Kluwer Academic, 1995.

5. $\quad$ Denzin, N.K. Interpretive Interactionism. Newbury Park, CA: Sage, 1989.

6. $\quad$ Dewey, T. Experience and Education, New York: Macmillan, 1938.

7. Garvin, D.A., Making the case: Professional Education for the World of Practice, Harvard Magazine, September-October 2003.

8. Gutek, G. L., Historical and Philosophical Foundations of Education: A Biographical Introduction, $\left(2^{\text {nd }}\right.$ Ed.). Upper Saddle River, NJ: Merrill/Prentice Hall, 1997.

9. Malcom, S. M. . Equity and Excellence through Authentic Assessment. In G. Kulm \& S. M. Malcom (Eds.), Science assessment in the service of reform. Washington, D.C.: American Association for the Advancement of Science Press. (Now published by Lawrence Erlbaum), 1991.

10. Saphier, J., \& Gower, G. . The Skilful Teacher .Journal of Pedagogy, Pluralism \& Practice, 1. Lesley College, Cambridge, MA,1997.

11. Shavelson, R.J. What we've learned about assessing hands-on science. Educational Leadership, 49, 20-25, 1992.

12. Stake, R. E.. Program evaluation, particularly responsive evaluation. Keynote address at the conference, New trends in evaluation, Institute of Education, University of Goteborg, Sweden, 1973.

13. Williams, Virginia, H., Aleong, John, Merrow, Susan B. and Morse, Ellen, B., (1980), Teaching Nutrition with Films, Family and Consumer Sciences Research Journal, 3; vol. 8: pp. 261 - 268, 1980.

\section{APPENDIX 1}

\section{ATTACHMENT A: Evaluation}

There were 17 students who began the Institute -- two did not return after the first day; two were asked to leave because of poor behavior at the end of the third week. Thirteen students completed the evaluation. A composite of the evaluation results follows:

SA-Strongly Agree, $\mathrm{A}=$ Agree, and $\mathrm{D}=$ Disagree in $\% \mathrm{n}=13$

\begin{tabular}{|c|c|c|c|}
\hline & SA & A & $\mathrm{D}$ \\
\hline 1. Subjects and topics were related to Transportation. & 46 & 54 & \\
\hline 2. Faculty and presenters provided sufficient explanation of the concepts. & 62 & 38 & \\
\hline 3. The speakers presented material in an organized manner. & 69 & 31 & \\
\hline 4. The speakers used examples to clarify the material presented. & 69 & 31 & \\
\hline $\begin{array}{l}\text { 5. The speakers and faculty provided insight and information about careers in the field of } \\
\text { Transportation. }\end{array}$ & 69 & 31 & \\
\hline 6. I was academically challenged by the activities, exercises and case studies provided. & 31 & 62 & 7 \\
\hline 7. The training at the Institute was beneficial. & 62 & 31 & \\
\hline 8. I would recommend the Institute to classmates and colleagues. & 16 & 46 & 38 \\
\hline $\begin{array}{l}\text { 9. I would seriously consider a career in the field of transportation based on my experience in } \\
\text { this workshop. }\end{array}$ & 46 & 38 & 16 \\
\hline 10. The faculty allowed you to express your ideas freely on ways to improve the workshops. & 38 & 46 & 16 \\
\hline
\end{tabular}

The following are examples of suggestions and recommendations received from students on the evaluation questionnaire:

Student Response 1: Get instructors who have more patience. Get students with more discipline. Have more field trips. If students behave badly, split them up from the rest of the group.

Student Response 2: We should better discipline the misbehaved and disrespectful students so that the good ones are able to go on fun trips just because more hands on experience. 
Student Response 3: I suggest students are chosen based on their academics and behavior to reduce the rate of bad behavior at the program.

Student Response 4: Thank you all for accepting me in this program.

There were nine students who did not respond to this question.

APPENDIX 2

\begin{tabular}{|c|c|c|c|c|c|}
\hline \multirow{2}{*}{$\begin{array}{l}\text { Date: } 07 / 19 / 2007 \\
\text { Overall Evaluation of the Program }\end{array}$} & \multirow[b]{2}{*}{$\begin{array}{c}\text { Strongly } \\
\text { Agree }(\%)\end{array}$} & \multirow[b]{2}{*}{ Agree (\%) } & \multirow[b]{2}{*}{ Disagree (\%) } & \multirow[b]{2}{*}{$\begin{array}{c}\text { Strongly } \\
\text { Disagree } \\
(\%)\end{array}$} & \multirow[b]{2}{*}{ Average } \\
\hline & & & & & \\
\hline \multicolumn{6}{|l|}{ SPEAKERS } \\
\hline Organized Speakers & 7 & 87 & & 6 & 2.933 \\
\hline Academically Challenged & 7 & 53 & 40 & & 2.667 \\
\hline Well Responded & 7 & 80 & 13 & & 2.933 \\
\hline Overall & 7 & 73 & 18 & 2 & 2.8443 \\
\hline \multicolumn{6}{|l|}{ STAFF } \\
\hline Career awareness & 33 & 47 & 13 & 7 & 3.067 \\
\hline Helpful & 13 & 53 & 27 & 7 & 2.733 \\
\hline Academic & 20 & 53 & 27 & & 2.933 \\
\hline Availability & 7 & 53 & 40 & & 2.667 \\
\hline Friendly & 13 & 60 & 27 & & 2.867 \\
\hline Knowledgeable & 13 & 67 & 20 & & 2.933 \\
\hline Enthusiastic & 7 & 67 & 20 & 6 & 2.733 \\
\hline Dorm Help & 26 & 47 & 20 & 7 & 2.933 \\
\hline Overall & 17 & 56 & 24 & 3 & 2.8583 \\
\hline \multicolumn{6}{|l|}{ ACTIVITIES } \\
\hline Transportation Knowledge & 7 & 67 & 20 & 6 & 2.733 \\
\hline Time for Projects & 13 & 53 & 27 & 7 & 2.733 \\
\hline Time for Participation & 13 & 60 & 27 & & 2.867 \\
\hline Practical Experience & 13 & 54 & 33 & & 2.800 \\
\hline Competition & 21 & 43 & 36 & & 2.857 \\
\hline Overall & 14 & 55 & 28 & 3 & 2.790 \\
\hline \multicolumn{6}{|l|}{ CAMPUS LIFE } \\
\hline Dorm Life & 64 & 14 & 22 & & 3.429 \\
\hline Nutritional Food & 36 & 21 & 36 & 7 & 2.857 \\
\hline Educational & 50 & 29 & 21 & & 3.286 \\
\hline Overall & 50 & 22 & 26 & 2 & 3.191 \\
\hline Overall Evaluation & 19 & 53 & 25 & 3 & 2.8897 \\
\hline
\end{tabular}

The average is around 3.0, most of which is due to Campus Life and Speakers. Overall, there were more students who "disagreed" than who "strongly agreed". 